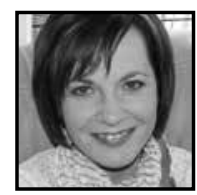

\title{
Teachers and Parents: Learning From Each 0ther Through Home Visits
}

\author{
Jennifer Heinrichs, University of Saskatchewan
}

\begin{abstract}
Using a narrative inquiry approach, the author examines how children, teachers, and parents benefit from the practice of conducting home visits. The author reflects on her own research and practice and imagines possibilities for enhancing parent engagement through home visiting. Central to this paper is how the knowledge gained from families through home visits can be used to enrich curriculum and create an inclusive learning environment in the classroom. Suggestions on how to help break down the barriers teachers and administrators face in planning for and conducting home visits are discussed.
\end{abstract}

\section{Why Home Visits?}

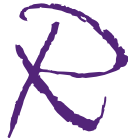
esearch demonstrates the positive impact parent engagement has on student learning and other educational outcomes (Epstein \& Van Voorhis, 2001; Henderson \& Mapp, 2002; Hoover-Dempsey et al., 2005; Jeynes, 2005; Redding, Langdon, Meyer, \& Sheley, 2004). With more immigrants moving into Saskatchewan communities, and increasing First Nations, Métis, and Inuit (FNMI) student enrollment, it is imperative that educators work to provide high quality education for all students. Increasing parent engagement within a school can assist in providing the best possible chance for all students to achieve greater success at school (Jeynes, 2005). It is through positive encounters that teachers and parents begin to form a relationship built on mutual trust. Parents are placing their confidence in us as educators with their precious children and believe in our abilities to do what is best for them. When we take 
the time to meet with them and listen to their stories, we show parents that we care about their children.

My research began with a review of the literature. I asked myself what is parent engagement? Parent involvement, common within schools, includes asking parents to act as a volunteer, birthday baker, play dough maker, chaperone, and so on, where parents are "serving only the school's agenda by doing the things educators expect them to do" (Pushor, 2010, p. 9). I learned that parent engagement, in contrast, is reciprocal - a partnership-where educators work alongside parents to enhance teaching and learning for children (Pushor, 2010). Parents are asked to "share their knowledge with teachers as together they make decisions about children's programs, the homework policy, the school's continuous improvement plan, or classroom curriculum delivery" (p. 9). The educator is not placed above the parent in a relationship such as this, positioned as expert knower of children, teaching, or learning. Instead, what the parent knows and what the teacher knows are both used in the schooling of a child.

It's not that family involvement is bad. Almost all the research says that any kind of increased parent interest and support of students can help. But almost all the research also says that family engagement can produce even better results-for students, for families, for schools, and for their communities. (Ferlazzo \& Hammond, 2009, as cited in Ferlazzo, 2011, p. 12)

As I entered into my own research, I found it important to differentiate between the two concepts because parent involvement does not require the educator to work collaboratively with parents. Further, it is parent engagement that leads to greater student success. Jeynes (2005) discovered, "Parental expectations and style may create an educationally oriented ambiance, which establishes an understanding of a certain level of support and standards in the child's mind" (p. 262). When children understand that their parents and their teachers believe they can achieve great success in school, it helps children to succeed.

Educators' assumptions and beliefs about families and students can be detrimental to a child and family's school experience. When we as educators place ourselves above students' families and judge them from what we have heard, we create deficit thinking about a family without really getting to know them. Flessa, Gallagher-Mackay, and Ciuffetelli Parker (2010) explained, "Deficit frameworks about families typically take the form of unsubstantiated assertions about families' supposed lack of interest in their 
children's education or lack of support for school-based goals and priorities" (p. 11). When educators act as the professionals who have the answers, voices of students and families are silenced.

Through my studies, I came to understand that when we reach out to a family and learn their true story, we can become a partner. All families love their children and truly want the very best for them. When we treat a family with respect and honour what they know about their child and what they have to say, we help them to become the best they can be.

Regardless of income level or education background, all families can-and dosupport their children's success... When schools engage families in ways that are linked to improving learning, students make greater gains. When families are engaged in positive ways, rather than labeled as problems, schools can be transformed from places where only certain students prosper to ones where all children do well. (Henderson, Mapp, Johnson, \& Davies, 2007, p. 3)

Where all students do well. What a terrific statement. If every school could help parents work to ensure all students do well, it would change the education system and our province for the good of all.

I began to look at my practice of conducting home visits with a new perspective. Home visits can provide a place for educators to begin to build relationships with all families.

I can't think of an easier way to begin building mutual liking and respect than to give parents a home-court advantage. Bonds of trust begin to build the moment I walk into a parent's home and compliment his or her hard work in raising an amazing child... The relationship starts when I take that first step toward the family instead of hiding behind my classroom door. (Smith, 2013, p. 76)

Successful home visits occur when educators accept everyone despite how they may differ from the teacher or the hegemonic notion of families. "When one group or type seems to be implicitly better than another, it is what sociologists call a hegemonic construction" (Heilman, 2008, p. 9). Hegemonic notions can prevent educators from looking at family's strengths. Instead, if believed, hegemonic notions can blind educators from seeing every family's ability to support their children in their own unique way. Learning from parents' stories can shift or change assumptions about families and help educators see all families' strengths. 
Home visits provide many benefits for the student, the parents, and the teacher. Meyer, Mann, and Becker (2011) outlined three key themes that arose in their research:

...First being in the homes provided the opportunity [for teachers] to learn about their students' backgrounds and home life, offering clues to help explain student's behavior in school...Second, teachers felt like the visits provided a more personal and comfortable home setting in which to get to know individual children.... The home visits also created a potentially less threatening opportunity for teachers to introduce themselves, and establish a relationship with parents. (pp. 194-195)

The research of Meyer and colleagues (2011) showed that home visits improved student attendance, classroom behavior, and academic performance:

The strongest impact appear[ed] to be related to teachers' perceptions of improved attitudes of both students' and parents' toward school, and the parents' attitude towards the teacher. Finally, results suggest that teachers believe, at least moderately, that the visits resulted in parents playing a more active role in supporting their child's learning. (p. 195)

This research helped me to fully understand why I believed in conducting home visits. When relationships are made with families, families feel safe and trust the school enough to share their stories. When teachers truly listen, we learn more and break down the assumptions and beliefs that can be damaging to a family's success in school.

\section{Perspectives on Home Visits}

\section{Through a Child's Eyes}

When I move backward in time, I recall bits and pieces of my kindergarten teacher's home visit. I do not remember particulars, but I can picture her smile, her voice, her laughter, and the attention she held for my mom, my little sister, and me. I could feel that she liked both me and my family; I remember liking her also. Later, on my first day of kindergarten, I was not afraid to go to school. In fact, my mother tells the story of walking me to school and thinking that she would get to bring me right to the kindergarten door. Instead, when we arrived at the school, I turned and said, "You can go now mom, I can go in by myself." I wonder now if it was that initial home visit that made me feel so comfortable and confident at such a young age of not yet five. 


\section{Through a Teacher's Eyes}

When I returned to the town I grew up in 22 years later to teach kindergarten there, I remember thinking that I could not learn anything from conducting home visits; I grew up in this town after all. However, because I still could bring to mind the feeling of my own kindergarten teacher visiting me, I knew it was an important piece of my job.

I was nervous about the format for the visits, so I planned every minute. I took ideas from other kindergarten teachers whom I believed had experience and knowledge greater than mine. I felt anxious going to my very first home visits. Would they be happy to see me? Would it be an uncomfortable setting for me? Would they think I was judging them? Would they be judging me? What if I said something wrong? What if the child did not want to see me? So many questions, so many fears. I determined one thing, however, I would place my focus on the child. The state of the house, the yard, the family make-up would not be important to me. I felt I needed to connect with the child and, if I did, everything else would go fine.

I now have conducted over 300 home visits in my 11 years of teaching in the small town in which I live. In the beginning of my career, it was the children who received the greatest benefit from these visits because I felt the children were able to make a connection with me. If there were tears the first day of school, I could distract them by asking questions about what was near and dear to them, "How are your pet rats, Tom and Jerry? How is your pirate play structure coming along? Did you go swimming last week?" These connections helped children know that they were cared about in my classroom, that they were important to me, that school was a safe place with this new person, their kindergarten teacher. "When teachers take time from their busy schedules and familiar school environment to visit a student's home, this further demonstrates that teachers really care" (Meyer et al., 2011, p. 192). I have never once needed to use a name tag for children on the first day of school, for visiting at least a half an hour or more with each of my students at their homes prior to school starting made their individual names and personalities unforgettable to me. When do we as teachers ever get to spend an entire half an hour with each of our students and their family? It was as I grew older and gained more experience that I learned about the benefits of home visiting for me as an educator.

Home visits taught me a whole story about a child. I was able to see first-hand how a child's reality was lived each day. I was then able to make adjustments to our kindergarten curriculum based on what I perceived their needs to be. Perhaps a child needed more space or time alone. Perhaps some needed more attention, more enrichment, a focus on science or music, or learning opportunities more inclusive 
of their culture or religion. I was able to take what I learned from my visits and enrich our classroom with authentic, meaningful activities. When we as teachers know more about our students, we are able to meet their needs and teach the whole child with compassion and greater understanding.

\section{Learning From a Parent}

The first time I went to Cassandra's ${ }^{1}$ house I was incredibly curious because Cassandra and I had attended school together but we were never close. Although we grew up in a very strong Mennonite community, I was not Mennonite. Her family religion and culture was different than mine. I wondered what I would learn from the home visit. I had many preconceived notions about this family. I had heard from other educators that they did not value education; among other assumptions as well, this statement made me the most nervous. How would I be accepted, as the teacher, even though I was someone Cassandra knew years ago? Armed with stories, our classroom mascot stuffed animal, a craft, a book for the child, and my camera, I took the familiar bus route to her place, past the farm where I grew up, to see her son.

When I think back to that first visit with Cassandra, I can recall a neat, comfortable, large older home that was at that time being renovated. It was moved onto a field surrounded by a large garden, pasture, and grain fields. When I knocked on the door, Cassandra answered, we smiled at each other but did not say much. I cannot remember clearly but I imagine I talked too much; I usually do when I am nervous. She led me into her living room where we sat down together to meet her son, Jacob. I read him a story, invited him to complete a craft, talked with him about what we would do in kindergarten, and admired the pretty little baby by Cassandra's side, and the little toddlers who quietly watched our visit with curiosity. Once I completed everything on my agenda and asked Cassandra if she had any concerns, I was off to the next house. I had a schedule to keep and I did not want to be late for any visits.

In my mind, the visit was a success and, perhaps it was, because I was invited to return many times to meet siblings in the years to come. I have visited this home six times, and have learned so much from the family about who they are, and what they believe and value. My home visits with Cassandra became more relaxed as the years went by. I knew what to expect, and I am certain she did as well. Near the end of my Master's degree, I began to think about what parents thought about home visits. Were the changes I was making to this practice effective for them? Were the parents noticing the changes to my practice and did they think they were positive changes? I decided that I wanted to pursue this topic in my Master's project through a narrative 
inquiry. I wanted to conduct recorded conversations with a parent to learn about her experiences with my home visits, to hear her perspective.

Through a parent's eyes. During my research, Cassandra stated, "Yeah you are more relaxed with your visits; it's not as (looking at her watch) okay now it's time to do this next part. Yes definitely, [more relaxed] now it's okay, well you have a question, we'll talk about that instead" (Recorded conversation, October 16, 2014). Over time, my focus shifted from what I wanted to accomplish for myself as teacher to what the child needed and wanted in the moment. I learned that the home visits were not about serving my needs but the needs of the child and the family. My needs became secondary and, because of this change, I gained understanding. I learned more about families and the child through giving up control of the visits.

With new understanding of the family, I realized that what I had heard from my teaching colleagues and what I had believed about this family previously was not truth. It was the teachers' story of the family (Huber, Graham, Orr, \& Reid, 2010). Huber et al. (2010) explained:

Stories of families are composed around dominant cultural, institutional, and social narratives; they are stories often experienced or told to individuals or families when they are seen by members outside of the family to be living in ways that conflict with dominant narratives. (p. 80)

Educators sometimes base their opinions about families on what colleagues or community members have told us. This is an unfair and unjust way to teach a child. Home visits help teachers "reinvisio[n] parents as caring experts on and active participants in the lives of their children" (Allen et al., 2002, p. 318). When we reach out to a family and learn their family story, their own intimate, knowing, and complex story of themselves (Huber et al., 2010) as they are living out their hopes and dreams, we can become partners. In this way we can reject the stories of families and accept the families' stories (Personal communication, D. Pushor, July 2014).

It was through our home visits that I learned that Cassandra's family valued education in many ways. Their children learned about the land by helping garden. They learned about taking care of animals because they took care of their cows, a pig, horses, and many dogs. They learned from their Bible every day through prayer and study. Such an education, learned in the home, is different from what a child learns through his/her formalized schooling. Both what is learned at home and what is learned at school contribute to a child's education, both are important and make up the child's education as a whole individual. Pushor (2013) explained: 
Our role as teacher, in this view of schooling as a support to a child's education, becomes one in which we walk alongside parents for the time we are with them to support them in achieving their life's work for their child. (p. 9)

Schooling is one form of education, however it does not include the entire learning in a child's lifetime of knowledge attainment. When a teacher truly believes this, she can begin to weave together a curriculum that supports learning from the home as well.

I also learned that this family, although different in religion and culture from me, was really not that different from my own family. Just as my family did, they valued hard work and working together to get farm work done. They had fun together. They talked of fishing trips to the lake and, like my husband and me, the parents worked hard to teach their children about their religion. Faith and attending Church was important to them. I came to understand that their children needed to attend their Church's extra sacred holidays because it helped form their identities. It was not that the children were absent from school because the family did not value education. As educators we often assume that when children miss school to attend a Church or family event, it is a day of no importance, a wasted day. However, I began to understand, through listening to Cassandra in her home, that these days were important because they helped the children feel belonging, and identity, as Old Colony Mennonite children. To ensure their culture's survival, their children needed to feel connected to it; they needed to learn to value it too. Attending these events built fellowship, connections, pride, and love for their culture and community. I would never have learned all this through school interactions with this family. The home visits provided a different atmosphere, place, and feel. The focus was also not on many students but on one. These visits built trust between Cassandra and me and I naturally became a learner because of our many conversations together.

\section{Home Visits Providing Reciprocal Benefits}

When I asked Cassandra what she remembered about our home visits that was significant to her, she recalled:

A lot of excitement, the kids were thrilled at the thought that their teacher was coming to their house to see them. Not coming to talk to mom, coming for them. That was very significant for my kids. I know a few of my kids you didn't teach [because I home schooled them] and they were very disappointed that they never had that experience. (Recorded conversation, October 16, 2014) 
A child's first teacher has the awesome responsibility of introducing them to the life of school. When the first experience with the teacher is a positive one, a relationship naturally develops. This relationship will support many aspects of a child's learning journey. Jeynes (2011) concurred, "The elementary school teacher, in particular, should visit the home of all of her or his students to be cognizant of each child's strengths and weaknesses and to build a partnership with the parents" (Jeynes, 2006, 2010a, 2010b, as cited in Jeynes, 2011, p. 12). When a child witnesses a trusting, respectful relationship between their parents and teacher, they too become trusting of the teacher and more comfortable with her or him.

Home visits also help the parents. As Cassandra explained, "Most moms are willing to do whatever it takes to make the child more comfortable because kindergarten is a huge step, whether it's your first or fifth [child], or your last" (Recorded conversation, October 16, 2014). A home visit with the teacher can help a parent feel more at ease sending their child to spend many hours of their day apart from home with a new person. When I asked Cassandra how our home visits benefited her, I was awestruck at her answer:

It's made me more comfortable with teacher, parent, child interactions altogether because, like you said, we've had a relationship from way back and you do get preconceived notions. You become more relaxed when you come into my home as a, you come here as a guest, not a teacher... so I learned how to talk to you a little more freely and that has helped me with all the teachers. Just to know that, not to know because you do know that, they're people too, but to feel that a little more. (Recorded conversation, October 24, 2014)

The home visits helped Cassandra see teachers in a new light. She was more comfortable discussing issues with her children's teachers because of the interactions she had experienced with a teacher in her home. This learning was very valuable to me as an educator. I had not realized that our visits also benefited the parents.

It has taken me 11 years to realize that home visits not only benefit me, and the child, but they also can benefit the parent. Previously, when I would prepare for and conduct a home visit I would create an agenda for me. Now I wonder, why did I not spend more time attending to what was important to the parent? When I conduct home visits presently I continually remind myself to let the child and the parents take the lead, and I follow. In this way I hope that our visits benefit the parent as well. This is true engagement, where everyone benefits from the encounter. The conversations I had with Cassandra awakened me to this possibility. I wonder if other parents perhaps feel the same way. 


\section{Overcoming the Fears of Home Visits}

\section{For Parents}

Parents often are not sure about agreeing to a home visit. They are worried about being judged as failing to meet an educator's standards of proper parenting. Cassandra spoke about that:

Now I would say, it's not a big deal. Jennifer's not there to look at how messy your house is, she doesn't care about that. She's coming to make the kids more comfortable with her, and that's what I would tell them. I know the first year or two I was a little nervous too. I was like, "Oh my house!" I mean we were in renovations. Oh my goodness! When you came over you weren't looking all over the place, you were going in to sit down and do your thing....have fun. I was like okay, it's okay. (Recorded conversation, October 16, 2014)

The family deserves to feel valued and important. As a teacher you are arriving as a guest in the family's home and this position changes the dynamic of the encounter. This is an important aspect of home visits. When a parent arrives in our classroom, it is our turf and we are welcoming them as guests; we are in control and it is our agenda that is being served. When we are the guests, the roles are reversed. What can we learn from the parents and family? What can they learn from us? Pushor (2007) explained:

Being guests means learning about the community which educators are entering, spending time and energy to know the context, the history, the culture(s), and particularly the people who reside there. Educators as guests ask what they can learn from parents and community members about their children and about teaching and learning, rather than positioning themselves as people with expert knowledge to share. (p. 10)

When teachers practice the guest role, we then realize how to be a host when our children's parents arrive in our classrooms. We can welcome them in, and create time for important conversations about the children and their learning. The partnership that develops is thus richer and more meaningful for the parents and the teacher.

\section{For Administrators and Teachers}

Many administrators and teachers are reluctant to engage in or afraid of the practice of home visits. They feel that when it is not something for which the school divisions make time or allow payment, it is unnecessary. Furthermore, some administrators are 
afraid for the safety of their teachers because, in some instances, teachers are visiting neighbourhoods in which the context of poverty plays out with high crime rates or other social issues. This assumption that homes and neighborhoods are unsafe is one that is worthy of challenge. In reference to our students' homes, Brizard (as cited in Mathews, August 18, 2011) stated, "Our students go there every day. Why can't we?" (n.p.). If our students' homes are safe for them, why are they not also safe for us to visit, especially when we follow well-planned protocols for home visits?

Teachers who are afraid of being judged, as I thought I may be, who are afraid of what to say, or of how to fill the visit up with conversation for a half hour can focus, as I did, on the children. When we walk through the door and listen unhurriedly to the child talk, it makes the child feel special and valued. When we share a bit of ourselves with the child and their family, it helps the family see us as a partner, a friend, someone who can be trusted. I have found that no matter how anxious I was about the visit, when I gave my attention to the child the visit went well. Almost every child will speak of the home visit at some point in our year together. "Remember, Mrs. Heinrichs, when you came to my house and we played with my kittens? Or, "... we went to see my new baby goats?" Or, "... we had ginger snaps and iced tea?" Or, "... we sat in my garden and you watched me do somersaults on the trampoline?" Anyone who has ever worked with a small child can attest to the fact that children long to share their accomplishments with important people in their lives. How great for teachers to be the cheerleaders for so many precious little people!

Visiting families in their homes can be extremely beneficial if educators approach the experience with care. An initial telephone call to each of the families is important. The teacher can explain s/hewould like to visit in the family's home if they are comfortable. The teacher can also suggest to the family that, if they would prefer, they could meet at a nearby park, restaurant, or at the school. It is essential that teachers explain that the visit is focused on meeting the child and learning from the parent about their child in order for the teacher to teach the child to the best of her/his ability. The message that the teacher wants to portray is that the parent has the most knowledge of this child and is the expert; the teacher is coming to learn from this expertise.

Rose, a pre-kindergarten colleague, explained that she will always be an advocate of home visits because of her experience with one particular mom. This mom had a little girl who was experiencing difficulties in school. Because the mom did not attend parent teacher conferences, Rose decided to ask the mom if she could visit the family's home. The mom agreed. A very quiet, unsure, frightened mom became open, honest, and engaged in their conversation. Rose believed that this mom had a 
history of negative school experiences and was not comfortable in a school setting. Differently, in her home where she belonged and knew safety, she was able to open up to Rose in ways that benefited everyone involved. Rose noted that it was often at home visits, rather than in school, that she learned the most about her students (Personal communication, October 2014). Lawrence-Lightfoot (2003) concurred, "The best way to communicate empathy for parents, and to keep the child in focus, is to mine the parent's wisdom about their child" (p. 68). When educators ask parents for advice and truly listen to their knowledge of their child, parents are pleased to share what they know.

\section{Using Home Visits to Inform Curricula}

Knowledge about families gained through home visits can then be used in the classroom to make curricular decisions. The teacher can ask parents to share their family's culture-a special dish for Chinese New Year, a jingle dress from a powwow, or a story read or told in class by a parent-ensuring that all children and families are reflected in the curriculum and that everyone is seen to be equally valued and important.

When resources only include the dominant culture and religion of a community, many children are unable to see themselves in the curriculum. When classrooms honour only families who are traditional or hegemonic in form, children from "other kinds of families" (Turner-Vorbeck \& Marsh, 2008), or families who are not composed of a mother, father, and two or three children, will not feel valued when they are unable to see themselves in their classroom environment, literature, discussions, and activities. When educators truly believe in high quality education for all, they can work to provide the best possible chance for students' success and well-being by acknowledging and welcoming all families. Asking families to create a photo book about their family is one way to celebrate all kinds of families in the classroom (Eng, 2013).

When I visited each home this year I brought a small blank photo album to each family. I shared my family's photo story. I then asked each family to help the children create a story about their own individual families. I invited them to include pictures of everything that is important to the child and their family. Once these books were complete, we placed them in two special baskets in our reading corner. These little books are the books that the children read the most. I will often find two or more children reading together, talking about their families and learning from each other. The message we have created for my students is, we are all important, we are all special, 
and let's celebrate our families together. Home visits can provide the teacher with essential learning about a child's culture or family which can inform classroom curriculum.

\section{Learning From Home Visits About Parent Engagement}

In our recorded conversations during this narrative inquiry, I asked Cassandra for input on my home visit practices and then I invited further input regarding any of my current teaching practices. She offered a few wonderful ideas on how I could engage parents more greatly. In June, I invite new kindergarten children to visit our classroom for one hour. I introduce myself, read them a story, ask them to explore the classroom, and to play with the other children. Cassandra suggested that I include parents in the children's orientation visit in order to make everyone's transition into kindergarten easier. Picking up on her suggestion, I noted that I would like to have refreshments available and I wondered if I should also invite current kindergarten parents to join us. Cassandra thought that some current parents may come because "kindergarten is a big step for mom and child ... most moms are willing to do whatever it takes to make the child comfortable" (Recorded conversation, October 16, 2014). The parents with the past year's experiences of kindergarten could share with the new parents all they know about a child's first year in a formal school setting. Any questions parents are too shy to ask the teacher may be asked of a fellow parent.

Cassandra also thought that it definitely would be a good idea for me to visit a new child's home when they enroll mid-year in kindergarten. Reflecting on the home visits I have done in the past, I wonder now why I did not think to ask new families if I could come to their home for a home visit. Why did I not break out of the mold of only doing home visits at the beginning of the year when time and mileage is allotted? I had a young student last year who started in January. I did not ask to visit the home. However, this little girl and her family became our family's neighbours in June and, after many conversations together, we have become friends. Her father is Chinese and her mother Filipino. I learned that the father is Buddhist. He taught me some valuable, beautiful lessons on Buddhist faith, lessons that dispelled some of my misconceptions about this faith. Once again, I learned we are more alike than different, but if I had never engaged in our rich conversations, I would have never known. I just wish I had asked to visit with them when their child was still my student; I would have then had the chance to contribute my learning from this father and family to our classroom curriculum. 
This year, in contrast, when a little girl transferred to our school in October, I immediately asked the mother if I could come and visit. I was surprised when she quickly responded with a yes. The relationship I had before the home visits with the child was definitely different than the relationship I have now. I believe that our relationship connected us more deeply and gave me greater knowledge concerning the child. I am now more privy to the child's strengths, loves, fears, personality, family bonds, and small triumphs. It is in their home that children are able to shine and their true spirit often is displayed. Sometimes classrooms can be difficult to navigate and a child struggles to let his or her true spirit emerge. This little girl has some social difficulties and yet I feel like I have patience with the behavior; could it be because of our home visit?

A final possibility for integrating home visits more deeply into my practice may be with having parent teacher conferences in homes rather than at school. I asked Cassandra for her opinion on this idea. She expressed that having parent-teacher interviews in families' homes would be a wonderful change. "If the parents have something that they would like to be brought up... they might feel more comfortable bringing up any small issues that they have if they are in their own home" (Recorded conversation, October 16, 2014). I just recently completed my November parent-teacher conferences and only two parents were unable to attend the interviews. Perhaps I should be calling these parents and asking them if they would prefer I come visit them in their homes instead of them coming to school? I wonder why the two families did not attend the interviews. Was it because of their large families and so many little ones? Perhaps there may be no one to take care of the babies if they leave and come to interviews? Perhaps they are not comfortable on the school landscape? I will only know if I call them and make the offer to come to them instead.

\section{Closing Thoughts}

My research experience has caused me to look at home visits differently. I understand that walking through the family's open door is the first important step to beginning a relationship, a partnership, and a team. Administrators and teachers who believe all parents, despite their life circumstances, hold knowledge that is important and essential in teaching their child will work to build a relationship with their students' families. Building relationships with parents and families is the starting point in making the school an inclusive, welcoming place where success can happen for all. Home visits provide a comfortable, safe, and familiar atmosphere for children to meet their teacher, 
and for parents to begin to teach the educator about their child. When teachers truly listen to parents' concerns, hopes, dreams, and stories, teachers gain knowledge from the families' lives which they can utilize to directly benefit the student. The wealth of resources parents and families can offer is worth the time and effort it takes to create partnerships that mutually benefit all-students, their families, and teachers.

\section{Note}

1. Pseudonyms are used throughout the article to protect the anonymity of parents, children, and colleagues.

\section{References}

Allen, J., Fabregas, V., Hankins, K. H., Hull, G., Labbo, L., Lawson, H. S., et al. (2002). PhOLKS lore: Learning from photographs, families, and children. Language Arts, 79(4), 312-322.

Eng, C. (2013). Rethinking practice: Families representing themselves. In D. Pushor \& the Parent Engagement Collaborative. (2013). Portals of promise: Transforming beliefs and practices through a curriculum of parents (pp. 193-203). Rotterdam, NL: Sense Publishers.

Epstein, J.L., \& Van Voorhis, F.L. (2001). More than minutes: Teachers' roles in designing homework. Educational Psychologist, 36(3), 181-193.

Ferlazzo, L. (2011). Involvement or engagement? Educational Leadership, 68(8), 10-14.

Flessa, J., Gallagher-Mackay, K., \& Ciuffetelli Parker, D. C. (2010). “Good, steady progress": Success stories from Ontario elementary schools in challenging circumstances. Canadian Journal of Educational Administration and Policy, 101, 2-38.

Heilman, E. (2008). Hegemonies and transgressions of family: Tales of pride and prejudice. In M. Miller Marsh \& T. Turner-Vorbeck (Eds.), (Mis)Understanding families: Learning from real families in our schools (pp. 7-27). New York: Teachers College Press.

Henderson, A. T., \& Mapp, K. L. (2002). A new wave of evidence: The impact of school, family and community connections on student achievement. Austin, TX: Southwest Educational Development Laboratory (National Center for Family \& Community Connections with Schools). Retrieved from: http://www.sedl. org/connections/resources/evidence.pdf.

Henderson, A. T., Mapp, K. L., Johnson, V. R., \& Davies, D. (2007). Beyond the bake sale: The essential guide to family-school partnerships. New York: The New Press.

Hoover-Dempsey, K.V., Walker, J.M.T., Sandler, H.M., Whetsel, D., Green, C.L., Wilkins, A.S., et al. (2005). Why do parents become involved? Research findings and implications. The Elementary School Journal, 106(2), 105-131.

Huber, J., Graham, D., Murray Orr, A., \& Reid, N. (2010). Literature conversations for inquiring into the influence of family stories on teacher identities. In M. Miller Marsh \& T. TurnerVorbeck (Eds.), (Mis)Understanding families: Learning from real families in our schools (pp. 79-94). New York: Teachers College Press. 
Jeynes, W. H. (2005). A meta-analysis of the relation of parental involvement to urban elementary school student academic achievement. Urban Education, 40(3), 237-269.

Jeynes, W.H. (2011). Parental involvement research: Moving to the next level. The School Community Journal, 21(1), 9-18.

Lawrence-Lightfoot, S. (2003). The essential conversation: What parents and teachers can learn from each other. New York: Random House.

Mathews, J. (2011, April 18). Should teachers visit student homes? The Washington Post. Retrieved from: http://www.washington post.com/blogs/class-struggle/post/ should-teachers-visit-student-homes/2011/ 08/17/gIQApbzoMJ_blog.html

Meyer, J.A., Mann, M.B., \& Becker, J. (2011). A fiveyear follow-up: Teachers' perceptions of the benefits of home visits for early elementary children. Early Childhood Education, 39, 191-196.

Pushor, D. (2007). Welcoming parents: Educators as guest hosts on school landscapes. Education Canada, 47(4), 6-11.
Pushor, D. (2010). Are schools doing enough to learn about families? In M. Miller Marsh \& T. Turner-Vorbeck (Eds.), (Mis)Understanding families: Learning from real families in our schools (pp. 4-16). New York: Teachers College Press.

Pushor, D. (2013). Bringing into being a curriculum of parents. In D. Pushor \& the Parent Engagement Collaborative, Portals of promise: Transforming beliefs and practices through a curriculum of parents (pp. 5-19). Rotterdam, $\mathrm{NL}$ : Sense Publishers.

Redding, S., Langdon, J., Meyer, J., \& Sheley, P. (2004). The effects of comprehensive parent engagement on student learning outcomes. Cambridge, MA:FamilyInvolvement Network of Educators (Harvard Family Research Project). Retrieved from: http://www.gse. harvard.edu/hfrp/content/projects/fine /resources/research/redding.pdf.

Smith, S. (2013). Would you step through my door? Educational Leadership, 70(8), 76-78.

Turner-Vorbeck, T. (2008). From textbooks to the teachers' lounge: The many curricula of family in schools. In T. Turner-Vorbeck \& M. Miller Marsh (Eds.), Other kinds of families: Embracing diversity in schools (pp. 176-191). New York: Teachers College Press.

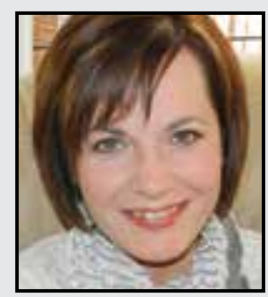

Jennifer Heinrichs completed her Master of Education degree at the University of Saskatchewan in December 2014. The focus of her studies was on parent engagement. She is passionate about engaging parents in schools and believes that this practice will help all students succeed to the best of their abilities. Jennifer has been an educator for 18 years. She has experience teaching kindergarten through grade 8 , as a teacher-librarian, core French, and music teacher. She has taught kindergarten for the past 11 years in a small community in Saskatchewan where she lives with her husband and three children. 